\title{
Mid Latitude Sporadic E-layer Variability during Ascending Phase of Solar Cycle 24
}

\author{
R. Atulkar ${ }^{*}$, P. A. Khan ${ }^{2}$, A. A. Mansoori ${ }^{3}$, P. K. Purohit ${ }^{1}$ \\ ${ }^{1}$ National Institute of Technical Teachers' Training and Research, Bhopal - 462002, MP, India \\ ${ }^{2}$ Department of Electronics and Communication Engineering, Islamic University of Science and \\ Technology, Pulwama, J \& K, India \\ ${ }^{3}$ Department of Electronics, Barkatullah University, Bhopal - 462026, MP, India \\ Received 16 July 2016, accepted in final revised form 6 September 2016
}

\begin{abstract}
The paper presents a comparative study of the ionospheric sporadic E layer parameters ( $\mathrm{fbEs}$, foEs, and h'Es) retrieved from ground based ionosonde at mid latitude station Yamagawa, Japan $(31.20 \mathrm{~N}, 130.370 \mathrm{E})$ during the ascending phase of 24th solar cycle i.e. during January 2012 to December 2014. The comparison between the E-region parameters has been carried out on a diurnal, seasonal, annual and day night basis. The diurnal maxima of foEs, fbEs, and h'Es are generally higher during high solar activity. From the present study it is found that the highest values of fbEs are observed during the summer while the lowest values are observed during autumn at mid latitude. Similarly, the highest values of foEs are observed during the summer season while the lowest values are recorded in autumn season. However, the highest values of h'Es are recorded during the spring and the lowest values are recorded in autumn. The variability of Es during the day and night time is also studied. The sporadic E can form and disappear in a short time during either the day or night. We have also studied the percentage occurrence of sporadic E. The occurrence of Es changes from year to year.
\end{abstract}

Keywords: Sporadic E; Blanketing frequency; Critical frequency; Wind shear.

(C) 2017 JSR Publications. ISSN: 2070-0237 (Print); 2070-0245 (Online). All rights reserved.

doi: http://dx.doi.org/10.3329/jsr.v9i1.28749 J. Sci. Res. 9 (1), 27-41 (2017)

\section{Introduction}

The E-region of the ionosphere is located about 80 to $160 \mathrm{~km}$ in altitude. The height can vary a little, and, along with electron density, depends on solar zenith angle and solar activity. During day hours, electron density can reach $10^{5} \mathrm{e} / \mathrm{cm}^{3}$. At night, when the supply of radiations from the sun is cut off, ionization levels drop to $10^{3} \mathrm{e} / \mathrm{cm}^{3}$. Basically, these ionization densities are expected under normal conditions. Sporadic E

* Corresponding author: roshniatulkar@gmail.com 
can occur during day or night time, and it varies with latitude, it can be associated with, meteor showers, thunderstorms, solar activity, and geomagnetic activity. Vertical wind shear is a widely accepted mechanism that explains the formation of mid-latitude Es [1-3]. Sequential sporadic E layers at low latitude in the Indian sector were presented by comparing Waltair $\left(\operatorname{dip} 20^{\circ} \mathrm{N}\right)$ with Trivandrum $\left(\operatorname{dip} 2^{0} \mathrm{~N}\right)$ and SHAR $\left(\operatorname{dip} 10^{0} \mathrm{~N}\right)$ [4]. They provided the experimental evidence for the wind shear theory for the formation of descending night time sporadic E layers by using the Ionosonde data. They concluded that the night time descending sporadic E layers are produced by the combined effect of the equator ward propagating gravity wave and the increased pole ward neutral wind which brings the ionization downward through the field line. Now a days some researchers considered Sporadic E (Es) as a very thin layer which occurs in clouds of relatively high electron density in the $\mathrm{E}$ region of ionosphere which significantly affect the HF and low-VHF communications [5-7]. Vryonides et al. studied the Es Layer characteristics over Cyprus station and analyzed the diurnal and seasonal occurrence of Es layer during a low solar activity period (January 2009 to August 2010) [8]. They observed that the sporadic E diurnal occurrence pattern is generally high during morning hours with a strong blanketing character, around noon, low in the afternoon and then reappears again during evening hours, sometimes persisting through the night. Sporadic-E occurrence is high in the northern hemisphere, peaking between $10^{\circ}$ to $30^{\circ}$ latitude; while in the southern hemisphere it is greatly depressed. Worldwide patterns indicate that Es occurrence depends on latitude [9]. The variations in velocity and direction of the neutral winds, in conjunction with the Earth's magnetic field, are important factors to account for the formation mechanism of mid-latitude sporadic-E [5,10-12]. Ernest and his associates studied the temporal and geographic variation of the sporadic E [13]. At equatorial latitudes Es is essentially a daytime phenomenon depending on seasons; at high latitudes Es is mainly present at night again with a low seasonal variation; at mid latitudes, Es shows a clear diurnal and seasonal variation. At mid latitudes and also at low latitudes the sporadic $\mathrm{E}$ (Es) layer formation depends essentially on the vertical wind shear which is associated with the tidal winds that almost always present between 100 and $160 \mathrm{~km}$ as inferred from incoherent scatter radar observations $[14,15]$. Haldoupis et al. proposed a new methodology, height-time-intensity (HTI) which is useful in measuring descent rates and tidal periodicities of Es [16,17]. Observations revealed that the diurnal and semidiurnal tides are the main agents that control the formation and altitude descent of sporadic E layers. Pignalberi et al. also used height-time-intensity (HTI) which describe the daily variability of the sporadic E (Es) layer, the top frequency (ftEs) and the lowest virtual height (h'Es) [18,19]. The height-time-Intensity (HTI) study, along with a fast Fourier transform analysis, showed that a semidiurnal periodicity characterizes the Es layer most accurately in June and July, while in August and September the daytime semidiurnal periodicity becomes weaker and the role of the diurnal periodicity is consequently highlighted. The wind shear theory only explains the principle of layer formation in the vertical plane but not in the horizontal plane. 
Hysell used Coherent Scatter Radar (CSR) at St. Croix, US Virgin Islands (USVI) in the Caribbean Sea, to observe low- and mid-latitude Es [20]. They revealed patchy structures of sporadic E (Es) elongated in E-W and/or NW-SE, and their movements in the directions perpendicular to the elongation azimuths. A thin and highly dense sporadic E layer called blanketing sporadic E which can occasionally block the upper ionospheric layers. Mid latitude sporadic E higher peaks occurred in the northern hemisphere in May, June, and July while minor peaks in December and January. Similarly, in the southern hemisphere higher peak occurred in the months of December, November and January [11,21-23]. Veenadhari et al. observed the occurrence of sporadic E at New Delhi and they did not find any clear relationship with magnetic activity [24]. Prasad and co-workers studied the diurnal, seasonal and day to-day variation of h'Es and foEs for three latitudes and observed that the sporadic E layer is absent in the early morning and post sunset hours [25]. The influence of solar and geomagnetic activity on mid and low latitude Es critical frequency foEs were investigated by many researchers [26-29]. Abe et al. studied the variability of foE in the equatorial ionosphere with solar activity at Ouagadougou (12.4 N, 1.5 W) [26]. They revealed that foE increases with the increase in solar intensity of the sun. Zhang and his group investigated the solar and geomagnetic activity effect on Es layer over low, mid and high latitude stations, during four solar cycles (1970-2010) and find that the effect of solar activity is different over different latitudes [27]. Pezzopane studied the effect of F10.7 solar flux over foEs and fbEs and find a high positive correlation of F10.7 solar flux with foEs and fbEs [28]. They also find that the correlation between F10.7 and fbEs is much higher than the correlation between F10.7 and foEs. Pietrella and his associates also studied the solar cycle effect on foEs over a mid-latitude station for three solar cycles and they don't find any significant dependence of solar cycle on occurrence of foEs [29]. Gwal et al. studied the occurrence of GPS amplitude fluctuations during January to December 2008 and they concluded that the amplitude scintillation is solar activity dependent [30]. The major problem in Es theory is to explain the diurnal variations and the seasonal and geographic distributions. In the present study Es layer behavior over mid latitude is studied using a modern digital ionosonde in Japan during 2012 to 2014.

\section{Data and Method of Analysis}

To accomplish this study we have used the digital ionosonde observations of three years i.e. from January 2012 to December 2014 carried out at mid latitude station Yamagawa, Japan. We have used the three ionospheric parameters for this i.e. foEs (Critical frequency of sporadic E-layer), fbEs (blanketing frequency of sporadic Elayer), and h'Es (height of sporadic E-layer) with one hour resolution. The ionosonde data used in this study were obtained from National Geophysical Data Center's (NGDC), Space Physics Interactive Prediction (SPIDR) website. A comparative study between the E-region parameters has been carried out on a diurnal, seasonal, annual 
and day night basis. Each year is divided into four seasons namely spring (March, April, May), summer (June, July, August), autumn (September, October, November) and winter (December, January, February) respectively. For this analysis we have used local time $(\mathrm{LT}=\mathrm{UT}+9$ hours) for calculation. We also computed the yearly percentage occurrence of Sporadic E.

\section{Results and Discussion}

\subsection{Monthly average diurnal variability of fbEs over Yamagawa}

The most important characteristics of the Es layer is its critical frequency (foEs) and blanketing frequency (fbEs). The monthly average diurnal variability of blanketing frequency of the sporadic E layer (fbEs) for each of the 12 months during the three years 2012 to 2014 is presented in Fig. 1.

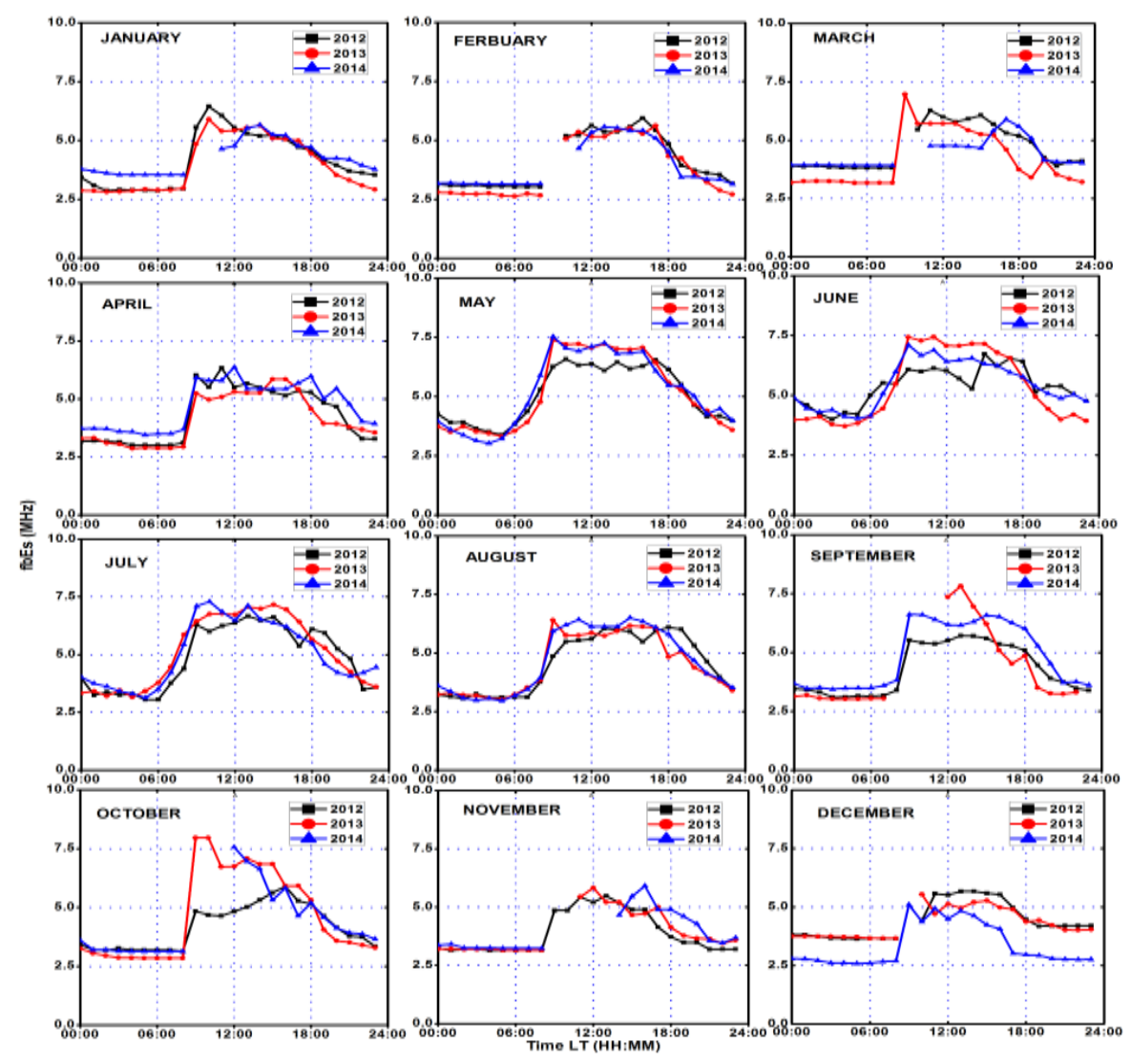

Fig. 1. Monthly average diurnal variability of Sporadic E-layer blanketing frequency (fbEs) at mid latitude station (Yamagawa) Japan during 2012 to 2014. 
The different color lines show the average variation of fbEs for each month of three different years. From the Figure we find that the fbEs observed highest peak values during the months of January, Feburary and December in 2012, during the months of March, June, September and October in 2013 while highest peak values for the year 2014 were observed during the months of April, May, July, August, June and September. The monthly diurnal average variability of fbEs shows higher values in the day time compared to night time. The diurnal pattern observed during all the months has same shape with occurrence of diurnal peak between the same times. The blanketing frequency (fbEs) reaches a peak value in morning hours 9 LT to $10 \mathrm{hrs}$ LT at Yamagawa.

\subsection{Monthly average diurnal variability of foEs over Yamagawa}

Critical frequency of sporadic E-layer (foEs) is an important parameter, which is very important in the radio wave communication. The monthly average diurnal variability of foEs during three different years is shown in figures 2. From the Figure we find that the Sporadic E layer critical frequency (foEs) observed highest peak values in the month of July for the year 2012. However the peak values of foEs recorded during the months March, May and June in 2013 and during the months of January, Feburary, August, September, October and November in 2014. The maximum foEs frequency fluctuated in the range of from $3.5 \mathrm{MHz}$ to $7 \mathrm{MHz}$ during morning to evening hours.
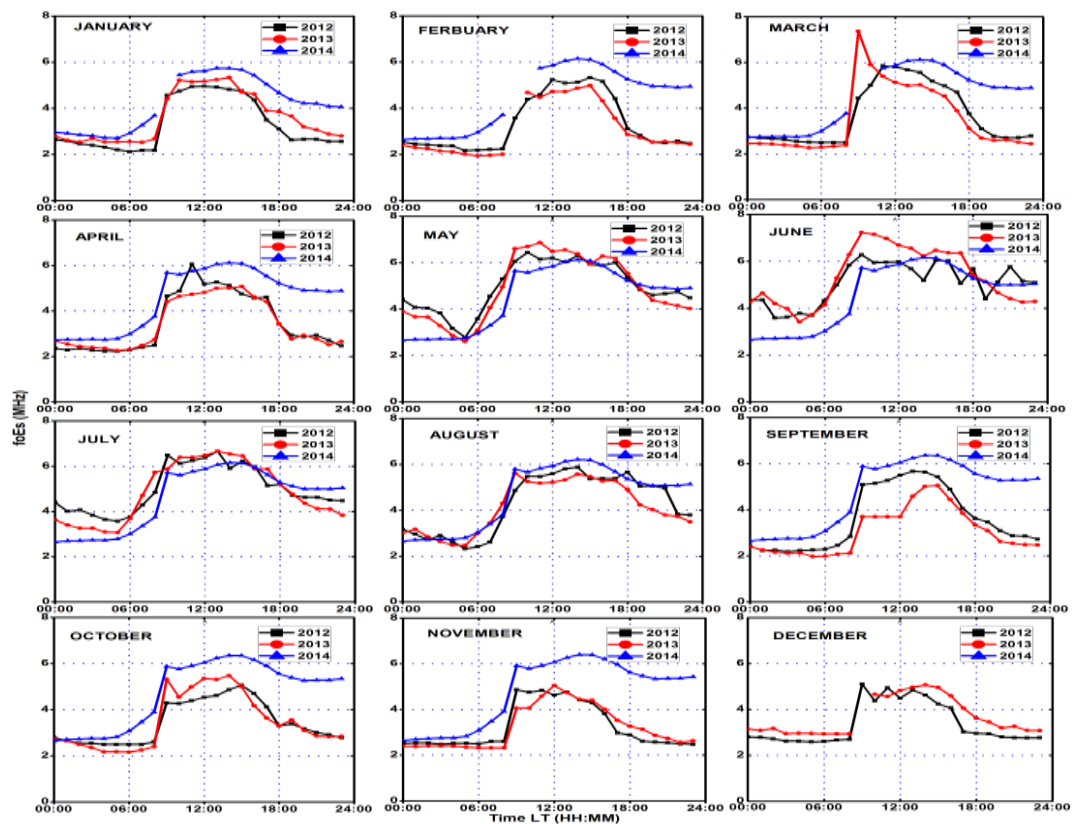

Fig. 2. Monthly average diurnal variability of Sporadic E-layer critical frequency (foEs) at mid latitude station (Yamagawa) Japan during 2012 to 2014. 


\subsection{Monthly average diurnal variability of h'Es over Yamagawa}

The monthly average diurnal variability of minimum virtual height of sporadic $\mathrm{E}$ layer (h'Es) at mid latitude station (Yamagawa) Japan during 2012 to 2014 is shown in Fig. 3. The h'Es values are higher during months of March and December in the year 2012, during the months of September and November in the year 2013 and during the months of April, May, September, October and November in the year 2014.
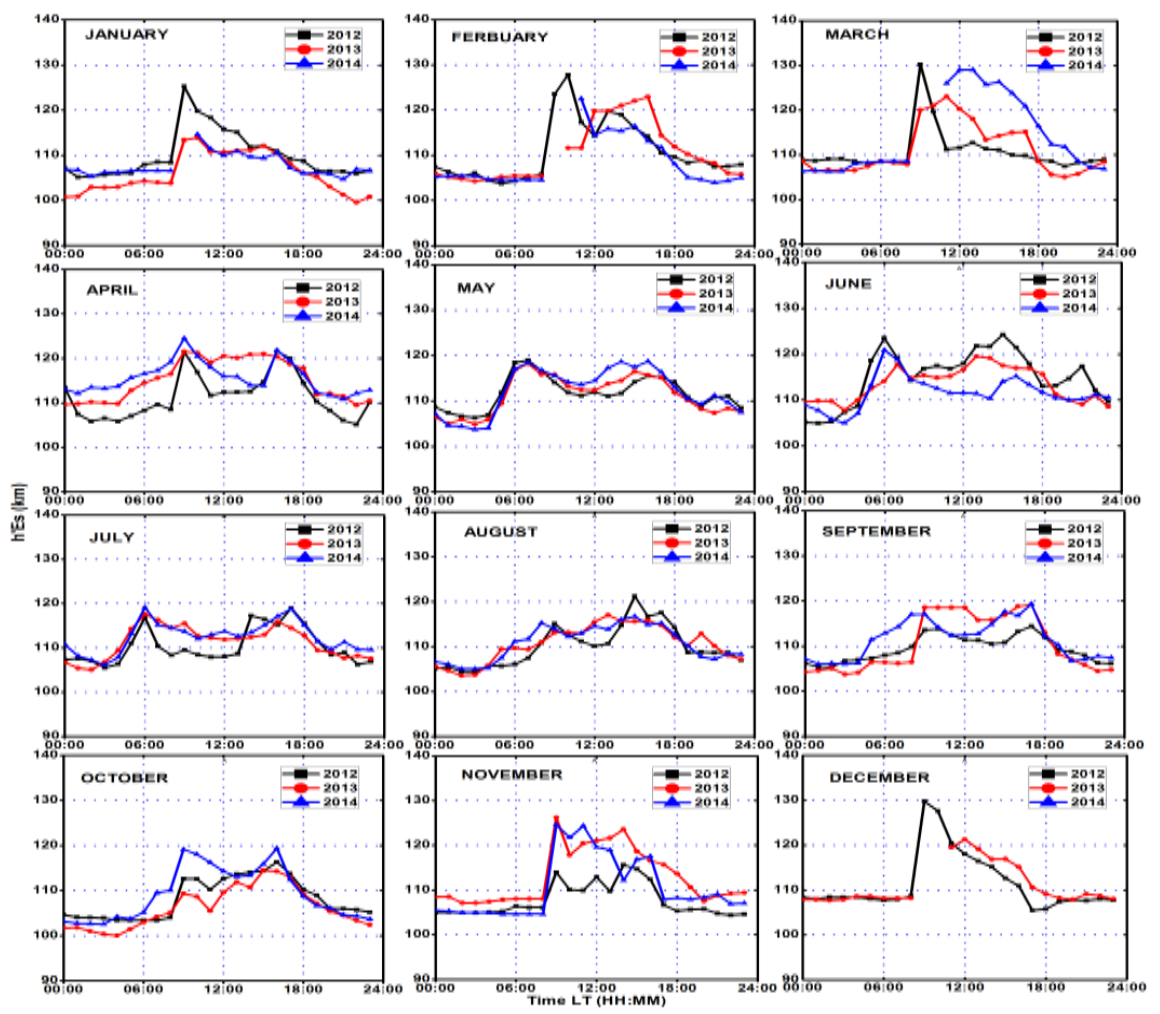

Fig. 3. Monthly average diurnal variability of sporadic E-layer minimum virtual height (h'Es) at mid latitude station (Yamagawa) Japan during 2012 to 2014.

\subsection{Monthly variability of fbEs over Yamagawa}

The month to month variability of fbEs for each month of the year 2012 to 2014 at mid latitude station (Yamagawa) Japan during 2012 to 2014 is shown in Fig. 4. The values of fbEs during each month are averaged to construct the Fig.4. It is observed that the monthly variation of fbEs is maximum during the month of June in the year 2012 and 2013 while in the year 2014 the maximum peaks were observed during the month of September. The minimum values of fbEs were observed during the month of 
November in the year 2012 and 2014 however, during the year 2013 the minimum values were observed during the month of February.

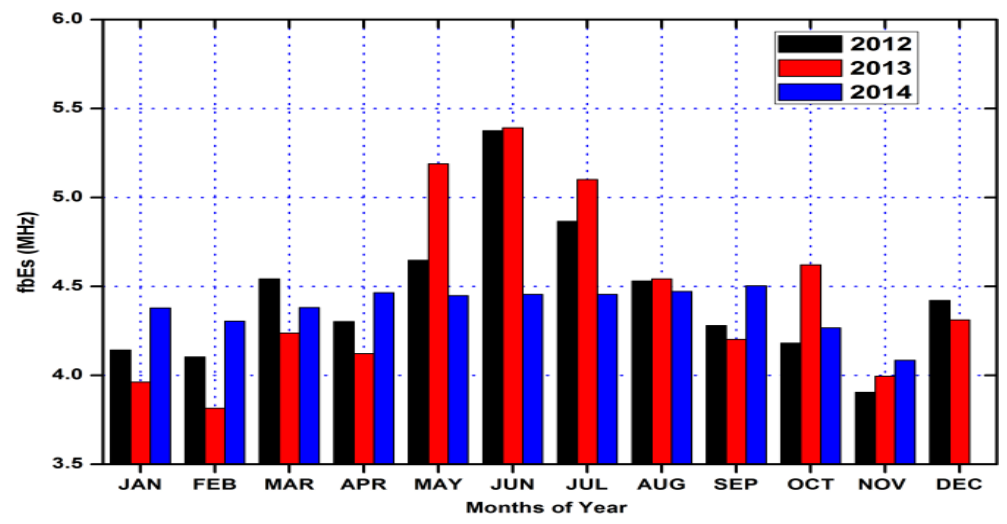

Fig. 4. Monthly variability of sporadic E-layer blanketing frequency (fbEs) at mid latitude station (Yamagawa) Japan during 2012 to 2014.

\subsection{Monthly variability of foEs over Yamagawa}

Monthly variability of Sporadic E layer critical frequency (foEs) at mid latitude station (Yamagawa) Japan during 2012 to 2014 is shown in Fig. 5. From the Figure we find that the monthly values of foEs is also maximum during the month of June in 2012 and 2013 with peak values 5-5.3 MHz. While the minimum values of foEs is observed during the months of Feburary and November, for all the three years.

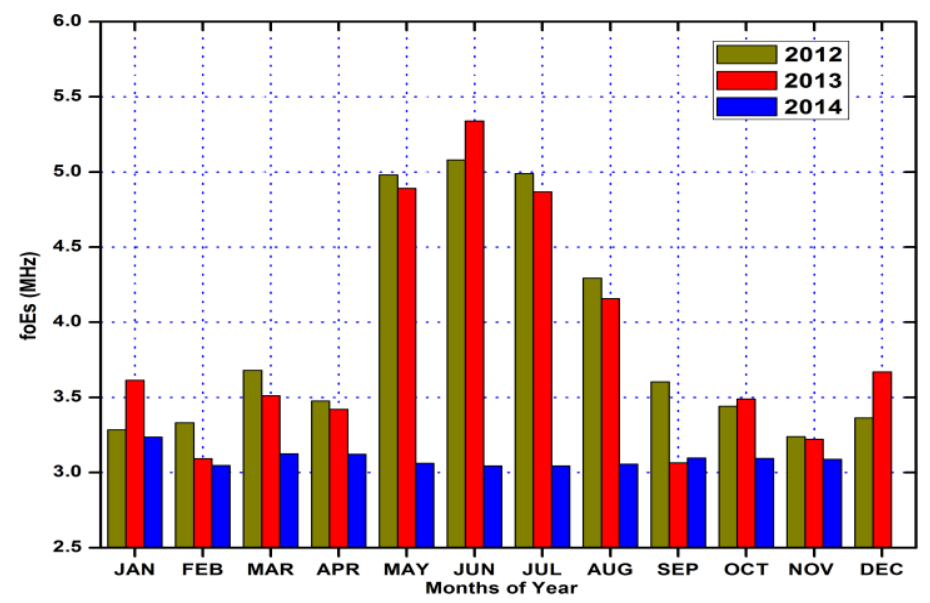

Fig. 5. Monthly variability of sporadic E-layer critical frequency (foEs) at mid latitude station (Yamagawa) Japan during 2012 to 2014. 


\subsection{Monthly variability of h'Es over Yamagawa}

Monthly variability of Sporadic E layer minimum virtual height (h'Es) at mid latitude station (Yamagawa) Japan during 2012 to 2014 is shown in Fig. 6. From the Figure we find that the monthly values of h'Es were maximum during the month of April while the minimum values were observed during the month of October in 2013 and during the month of February in 2012 and 2014.

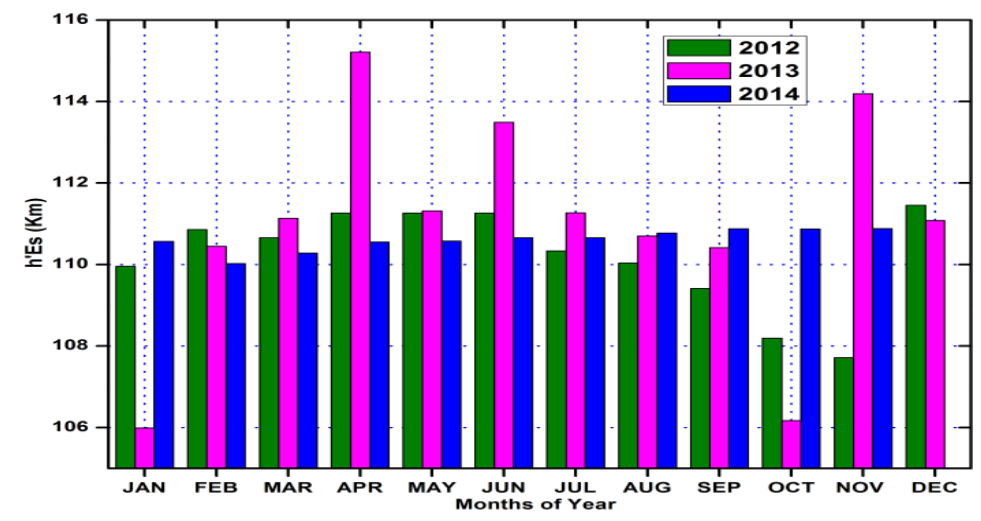

Fig. 6. Monthly variability of sporadic E-layer minimum virtual height (h'Es) at mid latitude station (Yamagawa) Japan during 2012 to 2014.

\subsection{Yearly average diurnal variability of fbEs over Yamagawa}

The yearly average diurnal variability of the fbEs, foEs and h'Es parameters have been determined for each year between 2012 to 2014. Fig. 7 shows the annual average diurnal variability of Sporadic E-layer blanketing frequency (fbEs) at mid latitude station (Yamagawa) Japan during 2012 to 2014. From the Figure we find that during the local morning hours around 0900-0930 to local evening hours around 1700 the annual occurrence of fbEs shows an increase from 2012 to 2013 and a decrease from 2013 to 2014 with respect to solar activity. The fbEs yealy maximum peak value recorded 5.5-6.8 MHz during 2012 to 2014 . The values of fbEs differ from each other in the individual years.

\subsection{Yearly average diurnal variability of foEs over Yamagawa}

Fig. 8 shows the annual average diurnal variability of Sporadic E-layer critical frequency (foEs) at mid latitude station (Yamagawa) Japan during 2012 to 2014. From the Figure we find that during the local morning hours around 0900-0930 annual occurrence of foEs shows a slight increase from 2012 to 2013, and a decrease from 2013 to 2014. The maximum peaks of foEs were recorded 4-6 MHz during 2012 to 
2014. The foEs values observed their maximum peaks in morning hours and minimum in the evening hours during each year.

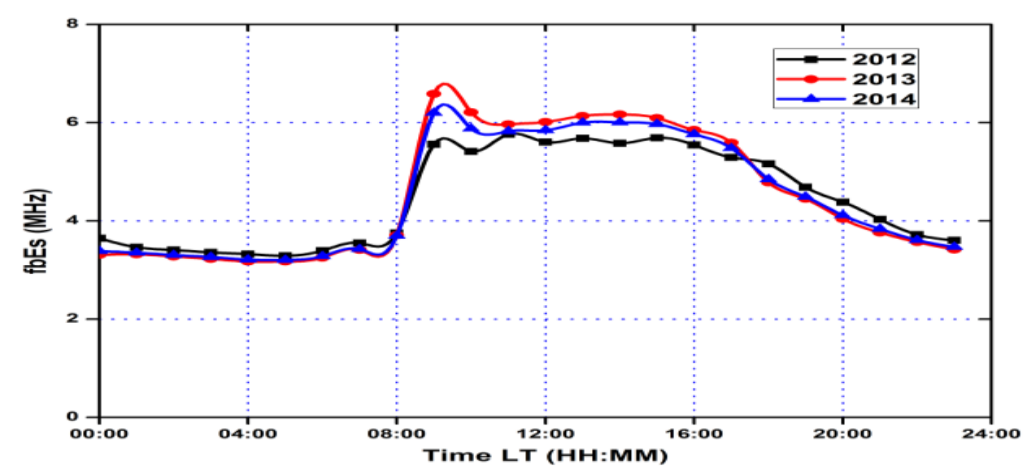

Fig. 7. The annual average diurnal variability of Sporadic E-layer blanketing frequency (fbEs) at mid latitude station (Yamagawa) Japan during 2012 to 2014.

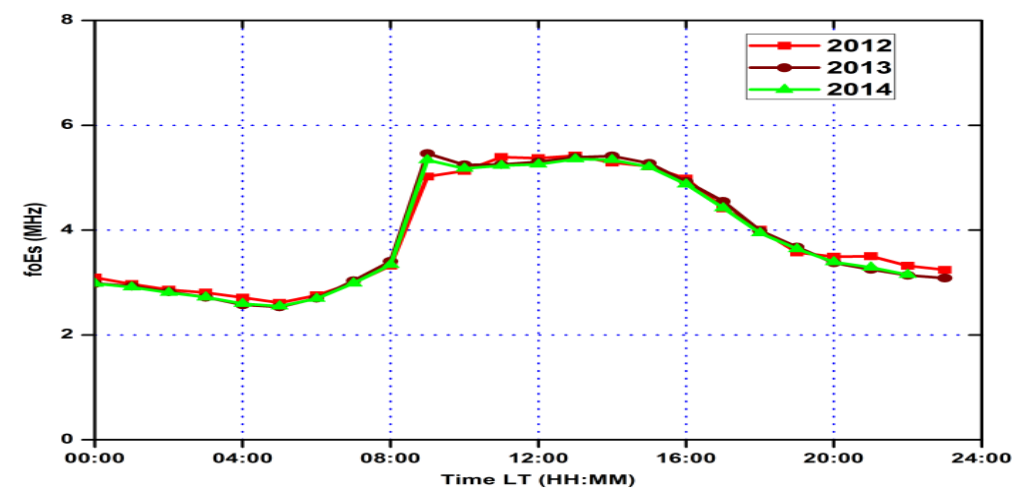

Fig. 8. The annual average diurnal variability of Sporadic E-layer critical frequency (foEs) at mid latitude station (Yamagawa) Japan during 2012 to 2014.

\subsection{Yearly average diurnal variability of h'Es over Yamagawa}

Fig. 9 Shows the annual average diurnal variability of minimum virtual height of sporadic E-layer (h'Es) at mid latitude station (Yamagawa) Japan during 2012 to 2014. Figure shows that during the local morning hours around 0900-0930 the yearly h'Es were highest in the year 2012 however during the day time the highest value of h'Es was observed in the year 2013 followed by 2014 and 2012. The h'Es values reached their maximum in morning hours and minimum in the evening hours during each year. The Maximum height was recorded between 115 to $120 \mathrm{~km}$. 


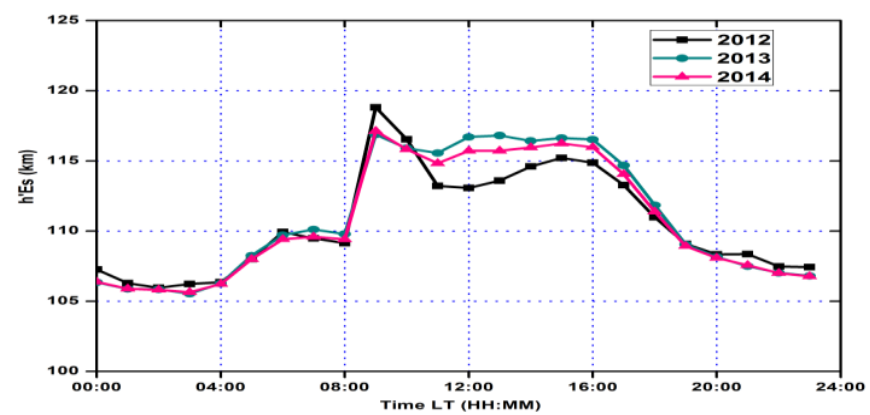

Fig. 9. The annual average diurnal variability of minimum virtual height of sporadic E-layer (h'Es) at mid latitude station (Yamagawa) Japan during 2012 to 2014.

\subsection{Seasonal variability of fbEs over Yamagawa}

The ionosphere varies throughout the year, from hour to hour, day to day, month to month and also from season to season. This is because the solar zenith angle (angle measured at the Earth's surface between the Sun and the zenith) has a seasonal variability, and because of the neutral atmosphere from which the ionosphere is created. Usually, the whole year is categorized into four seasons, i.e. spring (March, April, May), summer (June, July, August), autumn (September, October, November) and winter (December, January, February) respectively. The Seasonal variability of fbEs at mid latitude station (Yamagawa) Japan during 2012 to 2014 shows in Fig. 10. From the figure we find that the lowest values of fbEs were observed during autumn followed by winter and spring and the highest values were observed during the summer.

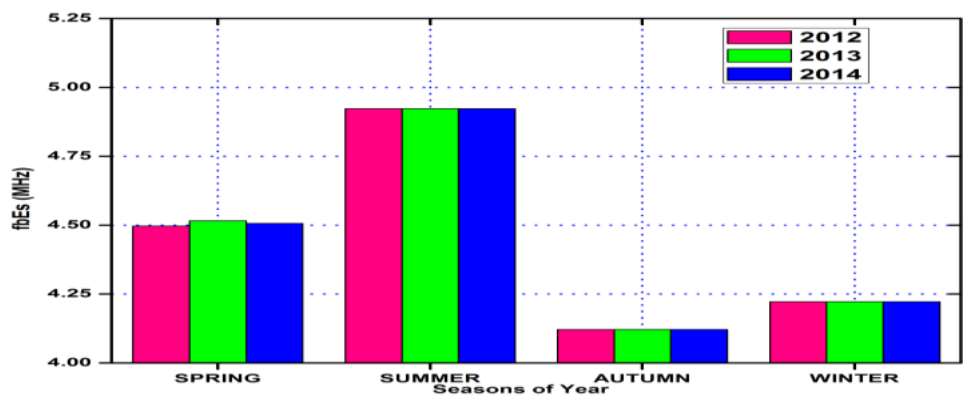

Fig. 10. The seasonal variability of fbEs at mid latitude station (Yamagawa) Japan during 2012 to 2014 .

\subsection{Seasonal variability of foEs over Yamagawa}

We have also studied the seasonal variability of foEs during four different seasons of the year 2012 to 2014. Fig. 11 shows the Seasonal variability of foEs at mid latitude 
station (Yamagawa) Japan during 2012 to 2014. From the figure we find that the highest values of foEs were observed during the summer followed by spring and lowest values were observed during autumn and winter.

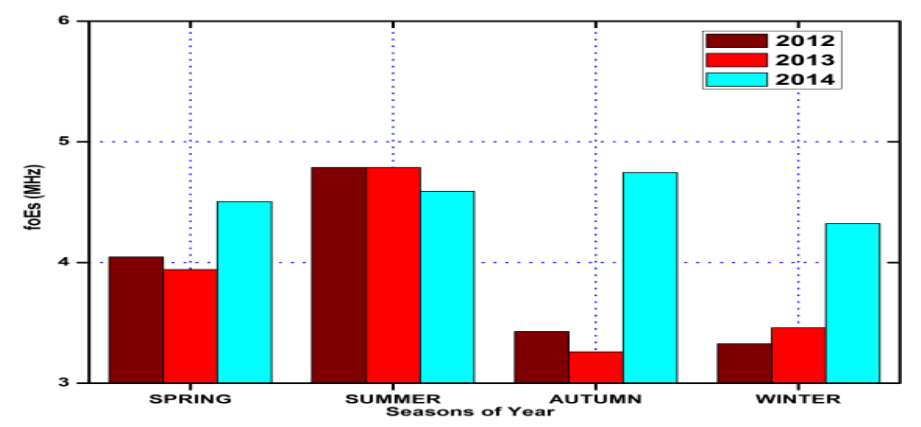

Fig. 11. The seasonal variability of foEs at mid latitude station (Yamagawa) Japan during 2012 to 2014 .

\subsection{Seasonal variability of h'Es over Yamagawa}

The seasonal variability of h'Es during four different seasons is presented in Fig. 12. The average seasonal h'Es shows higher values during the spring and summer season while the lower values were observed during winter and autumn season.

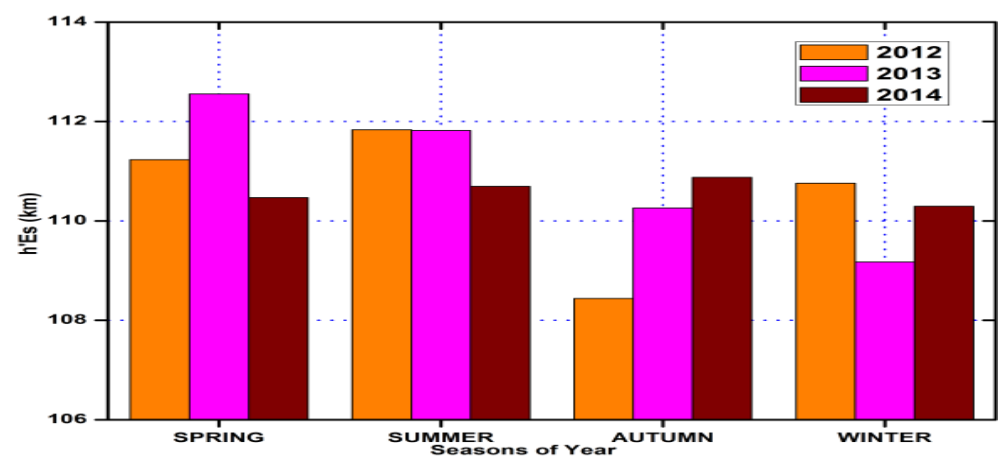

Fig. 12. The seasonal variability of h'Es at mid latitude station (Yamagawa) Japan during 2012 to 2014 .

\subsection{Monthly day and night time variability of fbEs, foEs and h'E over Yamagawa}

Figs. 13 to 15 present the monthly day and night time variability of fbEs, foEs and “h'Es over Yamagawa during 2012 to 2014. The number of occasions on which sporadic E occurred separately day time and night time during each months of the year 2012 to 2014 considered. The figure shows that the night time values of all the parameters are significantly lower than the day time values. The same feature is 
observed during all the years. This shows sporadic E occurs more intense during day time.

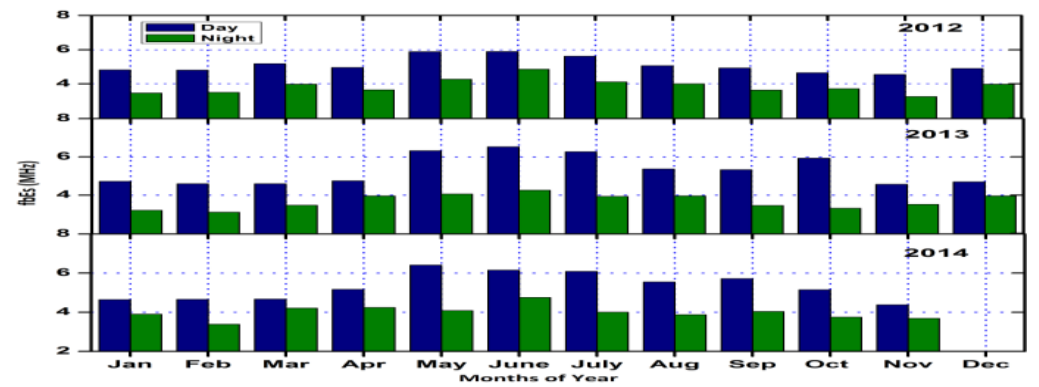

Fig. 13. The day and night time variability of fbEs at mid latitude station (Yamagawa) Japan during 2012 to 2014.

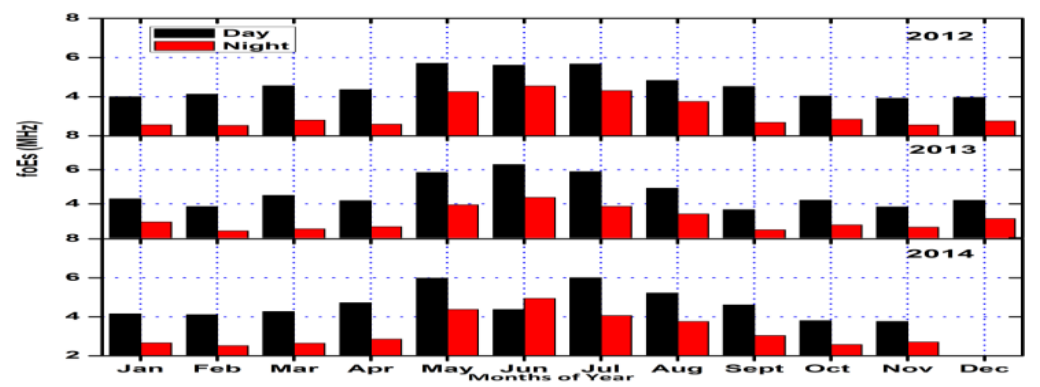

Fig. 14. The day and night time variability of foEs at mid latitude station (Yamagawa) Japan during 2012 to 2014.

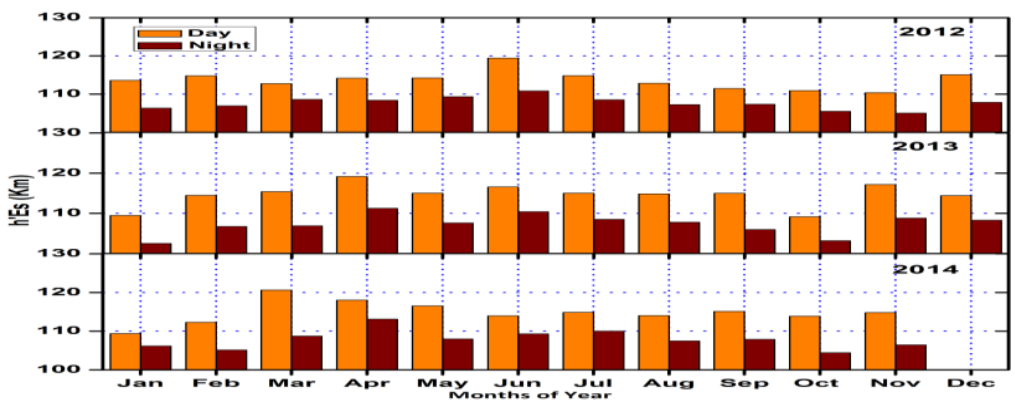

Fig. 15. The day and night time variability of h'Es at mid latitude station (Yamagawa) Japan during 2012 to 2014.

\subsection{Percentage occurrence of sporadic E over Yamagawa}

The yearly percentage occurrence of sporadic E is also computed individually during 2012 to 2014 which is shown in Fig. 16. From the figure we find that the maximum 
percentage occurrence of sporadic E is observed in 2013 with percentage occurrence more than $70 \%$ followed by the year 2014 with percentage occurrence $69 \%$ and the minimum percentage occurrence of sporadic E layer is observed in 2012 with percentage occurrence of $60 \%$.

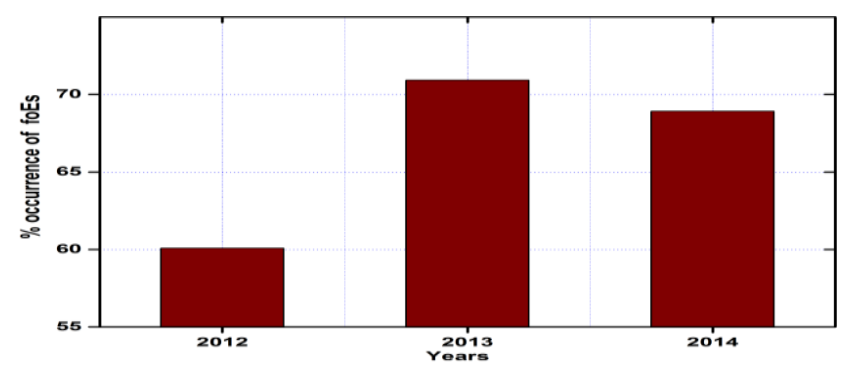

Fig. 16. Yearly variability of sporadic E-layer critical frequency (foEs) in term of percentage occurrence at mid latitude station (Yamagawa) Japan during 2012 to 2014.

In the present study, the daily, monthly, seasonal and annual variations of foEs, fbEs and h'Es indicate the effect of the variation of solar ionizing radiation with the Sun's zenith angle. The development of Es layers is due to the vertical shear of the horizontal wind according to the widely accepted wind-shear theory of mid-latitude sporadic E, foEs, fbEs, h'Es follows the variation of the solar zenith angle. Namely, the background electron density (electron density in the absence of wind-shear), which is modified by the wind-shear mechanism, changes with the solar zenith angle. As it is known, foEs is greater than foE due to the $\mathrm{U} \times \mathrm{B}$ electric field, which forces ions upwards from the height region, where the neutral wind is of W-E direction and moves ions downwards from that height region, where the neutral wind is directed E-W; the wind-shear is producing turbulence. Such a situation can be due to atmospheric gravity waves of appropriate vertical wavelength. The lowering of fbEs, foEs and h'Es associated with the decrease of solar activity proves only the role of solar ionizing radiation in the formation of Es layers by causing the decrease of the background electron density. As in the case of the daily variations, it also seems that the mean Wind-shear does not change with solar activity. The present results confirm that sporadic E parameters really depend on solar activity.

\section{Conclusion}

The main conclusions drawn from the present study are as follows:

$>$ The sporadic E-layer critical frequency (foEs), blanketing frequency (fbEs) and minimum virtual height (h'Es) tend to reach maximum between 08:00 and local noon while minimum after sunrise and two hours before the sunset. 
$>$ The fbEs, achieves its highest values during the months of September, October, May and June, foEs achieves its highest values during the months of March, May, July and August and h'Es achieves its highest values during the months of March and December while the lowest values of fbEs and foEs have been recorded during November and December and that for h'Es has been recorded during July, September and October.

$>$ The highest values of fbEs, foEs and h'Es are recorded during the summer season while the lowest values of fbEs, foEs and h'Es are recorded during the months of autumn.

$>$ Annual occurrence of fbEs shows an increase from 2012 to 2013 and a decrease from 2013 to 2014 during the local morning hours around 0900-0930 to local evening hours around 1700 .

$>$ Annual occurrence of foEs shows a slight increase from 2012 to 2013 and a decrease from 2013 to 2014 during the local morning hours around 0900-0930.

$>$ Yearly h'Es was highest in the year 2012 during the local morning hours around 0900-0930 however during the day time the highest values of h'Es were observed in the year 2013 followed by 2014 and 2012.

$>$ The day and night time variability of fbEs, foEs and h'Es were maximum during day hours while the minimum in the night hours.

$>$ Percentage occurrence of critical frequency of sporadic E layer was found maximum during 2013 and minimum during 2012.

\section{Acknowledgments}

The author (R. Atulkar) would like to thank National Institute of Technical Teachers' Training and Research, Bhopal for MHRD fellowship. The authors are highly thankful to National Geophysical Data Server, for providing various data sets required for this work.

\section{References}

1. J. W. Dungey, J. Geophys. Res. 64, 2188 (1959). http://dx.doi.org/10.1029/JZ064i012p02188

2. J. D. Whitehead, Nature 188, 567 (1960). http://dx.doi.org/10.1038/188567a0

3. J. D. Whitehead, J. Atmos. Terr. Phys. 20, 49 (1961). http://dx.doi.org/10.1016/00219169(61)90097-6

4. P. T. Jayachandran, P. Sriram, P. V. S. Rama Rao, and V. V. Somayajulu, Ann. Geophys. 17, 519, (1999). http://dx.doi.org/10.1007/s00585-999-0519-1

5. Z. Houminer, C. J. Russel, P. L. Dyson, and J. A. Bennet, Ann. Geophys. 14, 1060 (1996). http://dx.doi.org/10.1007/s00585-996-1060-0

6. D. D. Rice, J. J. Sojka, J. V. Eccles, J. W. Raitt, J. J. Brady, and R. D. Hunsucker, Space Weather 9, S12001 (2011). http://dx.doi.org/10.1029/2011SW000678

7. M. Pietrella, M. Pezzopane, and C. Bianchi, Adv. Space Res. 54, 150 (2014).

8. P. Vryonides, L. Economou, and H. Haralambous - PIERS Proceedings (Marrakesh, MOROCCO, 2011).

9. K. Davies, Ionospheric Radio (Peter Peregrinus Ltd., 1990) 31. 
10. J. D. Whitehead, Rev. Geophys. Space Phys. 8, 65 (1970). http://dx.doi.org/10.1029/RG008i001p00065

11. J. D. Whitehead, J. Atmos. Terr. Phys. 40, 1025 (1978). http://dx.doi.org/10.1016/00219169(78)90006-5

12. J. D. Whitehead, J. Atmos. Terr. Phys. 51, 401 (1989). http://dx.doi.org/10.1016/00219169(89)90122-0

13. E. K. Smith, Worldwide Occurrance of Sporadic E, National Bureau of Standards Circular 582, (1957).

14. J. D. Mathews, J. Atmos. Sol.-Terr. Phys. 60, 413 (1998). http://dx.doi.org/10.1016/S13646826(97)00043-6

15. C. Haldoupis, Space Sci. Rev. 168, 441 (2012). http://dx.doi.org/10.1007/s11214-0119786-8

16. C. Haldoupis, C. Meek, N. Christakis, D. Pancheva, and A. Bourdillon, J. Atmos. Sol.-Terr. Phy. 68, 539 (2006). http://dx.doi.org/10.1016/j.jastp.2005.03.020

17. C. Haldoupis, A Tutorial Review on Sporadic E Layers, in: Aeronomy of the Earth's Atmosphere-Ionosphere (Springer, 2011) Chapter 29, 2, pp. 381. http://dx.doi.org/10.1007/978-94-007-0326-1_29

18. A. Pignalberi, M. Pezzopane, and E. Zuccheretti, Ann. Geophys. 32, 1427 (2014).

19. A. Pignalberi, M. Pezzopane, and E. Zuccheretti, J. Atmos. Sol.-Terr. Phys. 122, 34 (2015). http://dx.doi.org/10.1016/j.jastp.2014.10.017

20. D. L. Hysell, E. Nossa, M. F. Larsen, J. Munro, M. P. Sulzer, and S. A. González, J. Geophys. Res.: Space Phys. 114 (A12) (2009). http://dx.doi.org/10.1029/2009JA014403

21. L. F. McNamara, The Ionosphere Communications, Surveillance and Direction Finding (Krieger publishing company, Malabar Florida, 1991).

22. J. M. Goodman, HF Communications, Science \& Technology (Van Nostrand Reinhold, New York, USA, 1992).

23. C. Haldoupis and K. Schlegel, J. Geophys. Res. 101, 387 (1996). http://dx.doi.org/10.1029/96JA00758

24. B. Veenadhari, R. S. Dabas, V. K. Vohra, D. R. Lakshmi, N. K. Sethi, and S. C. Garg, Study on Sporadic E Occurrences Observed at New Delhi with Modern Digital Ionosonde Proc. GA02, pp 0783, (2002). http://www.ursi.org/Proceedings/ProcGA02/papers/p0783.pdf

25. S. N. V. S. Prasad, D. S. V. V. D. Prasad, K. Venkatesh, K. Niranjan, and P. V. S. Rama Rao, Indian J. Radio Space phys. 41, 26 (2012).

26. O. E. Abe, A. B. Rabiu, and J. O. Adeniyi, Adv. Space Res. 51, 69 (2013). http://dx.doi.org/10.1016/j.asr.2012.08.010

27. Y. Zhang, J. Wu, L. Guo, Y. Hu, H. Zhao, and T. Xu, Adv. Space Res. 55, 1366 (2015). http://dx.doi.org/10.1016/j.asr.2014.12.010

28. M. Pezzopane, A. Pignalberi, and M. Pietrella, J. Space Weather Space Clim. 5 (2015). http://dx.doi.org/10.1051/swsc/2015031

29. M. Pietrella and C. Bianchi, Adv. Space Res. 44, 72 (2009). http://dx.doi.org/10.1016/j.asr.2009.03.006

30. A. K. Gwal, P. Bhawre, A. A. Mansoori, and P. A. Khan, J. Sci. Res. 5, 255 (2013). http://dx.doi.org/10.3329/jsr.v5i2.12724 